\title{
Metformin-induced activation of AMPK inhibits the proliferation and migration of human aortic smooth muscle cells through upregulation of p53 and IFI16
}

\author{
BIAO HAO ${ }^{1,2}$, YAN XIAO ${ }^{1,2}$, FANG SONG ${ }^{1,2}$, XIANGSHU LONG ${ }^{1,2}$, JING HUANG $^{1,2}$, \\ MAOBO TIAN $^{1,2}$, SHIYAN DENG ${ }^{1,2}$ and QIANG WU ${ }^{1,2}$ \\ ${ }^{1}$ Department of Cardiology, The Affiliated People's Hospital of Guizhou Medical University; ${ }^{2}$ Department of Cardiology, \\ Guizhou Provincial People's Hospital, Guiyang, Guizhou 550002, P.R. China
}

Received December 12, 2016; Accepted December 7, 2017

DOI: 10.3892/ijmm.2017.3346

\begin{abstract}
The proliferation and migration of vascular smooth muscle cells are significant in the development and progression of atherosclerosis and plaque rupture. Metformin is a widely used antidiabetic drug, which has been reported to inhibit cell growth and migration. The antiproliferative and antimigratory effects of metformin have been attributed to $5^{\prime}$ adenosine monophosphate-activated protein kinase (AMPK) activation. The purpose of the present study was to investigate the effects of metformin on primary human aortic muscle cells (HASMCs) in vitro and to clarify the underlying mechanism. We investigated the effectiveness of metformin in inhibiting the proliferation and migration of HASMCs in vitro using RNA extraction and reverse transcription-quantitative polymerase chain reaction (RT-qPCR), cell number counting, cell viability assay, cell cycle assay and cell migration assay. Through transfection with small interfering (si)RNA targeting p53 and interferon-inducible protein 16 (IFI16), the roles of $\mathrm{p} 53$ and IFI16 in these processes were evaluated. The present study demonstrated that $\mathrm{p} 53$, IFI16 and AMPK were upregulated in senescent primary HASMCs, which exhibited a decrease in proliferation and migration. In addition, metformin was able to activate $\mathrm{p} 53$, IFI16 and AMPK, in order to inhibit proliferation and migration of HASMCs. Furthermore, siRNA-mediated knockdown of p53 and IFI16 attenuated AMPK activation and reversed the suppressive effects of metformin. Notably, in response to metformin, the activation of AMPK was not observed in p53- and IFI16-silenced HASMCs. These results indicated that metformin-induced activation of AMPK suppresses the proliferation and migration of HASMCs by upregulating p53
\end{abstract}

Correspondence to: Professor Qiang Wu, Department of Cardiology, Guizhou Provincial People's Hospital, 83 Zhongshan Dong Road, Guiyang, Guizhou 550002, P.R. China

E-mail: provincialhospital@126.com

Key words: metformin, human aortic smooth muscle cells, p53, interferon-inducible protein 16 and IFI16. These findings suggested that metformin may have potential use in the treatment of atherosclerosis.

\section{Introduction}

Atherosclerosis is a complex, chronic progressive disease, and a major cause of mortality worldwide $(1,2)$. The atherosclerotic process comprises three steps: Fatty streak formation, atheroma formation and atherosclerotic plaque formation (3). Serious clinical consequences of atherosclerosis, including myocardial infarction and stroke, are caused by acute rupture of unstable plaques (4). The proliferation and migration of vascular smooth muscle cells are important in the pathogenesis of atherosclerosis and in the rupture of unstable plaques (5-7).

Metformin is a biguanide class drug, which is widely used for the clinical treatment of type 2 diabetes mellitus (8); its fundamental use is to suppress gluconeogenesis and promote glucose metabolism (9). Previous studies have reported that metformin exerts vascular protective effects beyond its role in treating diabetes $(10,11)$. A recent study indicated that metformin is associated with the suppression of diabetes-accelerated atherosclerosis (12). In addition, it has been suggested that metformin may have a role in preventing and treating atheroma, and protecting against plaque rupture (13). Furthermore, metformin may inhibit smooth muscle cell proliferation and migration $(14,15)$.

In response to metformin, ataxia telangiectasia-mutated (ATM) protein is phosphorylated at Ser-1981 (16). It has been reported that ATM activates p53 via phosphorylation of Ser-15, in response to DNA damage (17). p53 is regarded as a powerful suppressive factor that is capable of halting cell proliferation and inhibiting migration $(18,19)$. Previous studies have indicated that p53 serves a key role in metformin-mediated growth inhibition in numerous types of tumor cell (20-22). In addition, activated p53 can activate 5' adenosine monophosphate-activated protein kinase (AMPK) (17). The suppressive effects of metformin are closely associated with AMPK activation $(14,23)$, which can induce cell cycle arrest $(23,24)$. However, the signaling pathways and downstream effectors underlying the effects of metformin remain to be elucidated. 
As a member of the 200 protein family, interferon-inducible protein 16 (IFI16), has been reported to have a central role in regulating cell proliferation by interacting with various cellular modulators (25). p53 can upregulate IFI16 in human diploid fibroblasts (HDFs) (26), whereas knockdown of IFI16 results in a reduction of AMPK in HDFs (27). However, the molecular mechanism by which IFI16 upregulation is induced by metformin remains to be fully elucidated.

Based on these previous findings, the present study demonstrated that metformin inhibits the proliferation and migration of human aortic smooth muscle cells (HASMCs) via AMPK activation. In addition, the roles of p53 and IFI16 in metformin-mediated suppressive effects on HASMCs were identified. Notably, the present study provided a novel insight into the mechanisms underlying metformin-mediated HASMC proliferation arrest and migratory inhibition in atherosclerosis development and progression.

\section{Materials and methods}

Cell culture. Primary HASMCs were obtained from ScienCell Research Laboratories, Inc. (San Diego, CA, USA). According to the manufacturer's records, HASMCs were obtained from a donor, the details of which are as follows: Age, 20 weeks; sex, female; race, unknown. HASMCs were cultured in smooth muscle cell medium (SMCM; ScienCell Research Laboratories, Inc.) supplemented with 5\% fetal bovine serum (ScienCell Research Laboratories, Inc.), $1 \%$ smooth muscle cell growth supplement (ScienCell Research Laboratories, Inc.), $100 \mathrm{U} / \mathrm{ml}$ penicillin and $100 \mathrm{U} / \mathrm{ml}$ streptomycin. Cells were incubated at $37^{\circ} \mathrm{C}$ in a humidified atmosphere containing $5 \% \mathrm{CO}_{2}$.

RNA interference. p53 small interfering (si)RNA (sense, 5'-GCAUGAACCGGAGGCCCAU-3' and antisense, 5'-AUG GGCCUCCGGUUCAUGC-3'), IFI16 siRNA (a pool of 3 different siRNA duplexes: sc-35633A sense, 5'-CCACAAU CUACGAAAUUCA-3' and antisense, 5'-UGAAUUUC GUAGAUUGUGG-3'; sc-35633B sense, 5'-CCAUCCAGC AGUUUCUUCA-3' and antisense, 5'-UGAAGAAACUG CUGGAUGG-3'; sc-35633C sense, 5'-GGAAGGAGAUA AACUGAAA-3' and antisense, 5'-UUUCAGUUUAUC UCCUUCC-3'), control siRNA, control siRNA (fluorescein-conjugated), siRNA transfection reagent and siRNA transfection medium were purchased from Santa Cruz Biotechnology, Inc. (Dallas, TX, USA). Briefly, HASMCs $\left(1 \times 10^{5}\right.$ cells $\left./ \mathrm{ml}\right)$ were transiently transfected with siRNA (concentration, $0.06 \mathrm{mmol} / \mathrm{l}$ ) according to the manufacturer's protocol. After adding the siRNA, the cells were incubated for $5-7 \mathrm{~h}$ at $37^{\circ} \mathrm{C}$ in a $\mathrm{CO}_{2}$ incubator. A total of $48 \mathrm{~h}$ post-transfection, cells were processed for immunoblotting, cell cycle analysis and immunofluorescence, or were treated with various concentrations of metformin (Sigma-Aldrich; Merck KGaA, Darmstadt, Germany; dissolved in 1X PBS) and incubated for an additional $24 \mathrm{~h}$ at $37^{\circ} \mathrm{C}$. RNA-silenced HASMCs were treated with various concentrations of metformin $(0,10 \mathrm{mM})$ at $37^{\circ} \mathrm{C}$ for $24 \mathrm{~h}$ (RNA-silenced group; RNA-silenced + metformin group).

Senescence-associated $\beta$-galactosidase staining (SA- $\beta$-gal). The SA- $\beta$-gal activities of young (passage number 3 ) and old (passage number 7) HASMCs were detected using a SA- $\beta$-gal staining kit (Beyotime Institute of Biotechnology, Shanghai, China) according to the manufacturer's protocol. The number of blue cells (SA- $\beta$-gal-positive cells) and the total number of cells in six randomly chosen fields were counted to calculate the percentage of senescent cells using an ordinary optics microscope (Olympus Corporation, Tokyo, Japan). Percentage of senescent cells $=($ number of SA- $\beta$-gal positive cells/number of total cells) x $100 \%$.

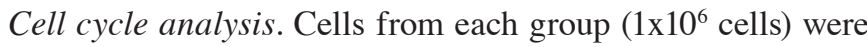
washed with PBS, trypsinized, centrifuged at $167.7 \mathrm{x}$ g at $4^{\circ} \mathrm{C}$ for $5 \mathrm{~min}$, resuspended in $3 \mathrm{ml} 75 \%$ ethanol and stored at $4^{\circ} \mathrm{C}$ overnight. The cells were then centrifuged, resuspended in $200 \mu \mathrm{l}$ PBS supplemented with $10 \mu \mathrm{g} / \mathrm{ml}$ RNase A and were incubated at $37^{\circ} \mathrm{C}$ for $30 \mathrm{~min}$. Subsequently, the cells were stained with propidium iodide (PI) solution $(0.1 \%$ sodium citrate, $0.1 \%$ Triton X-100, and $50 \mu \mathrm{g} / \mathrm{ml}$ PI; BestBio, Shanghai, China) at $4^{\circ} \mathrm{C}$ for $30 \mathrm{~min}$. Cell cycle progression was analyzed using a BD FACSCalibur flow cytometer (BD Biosciences, San Jose, CA, USA), and data analysis was conducted using FlowJo 7.6 software (FlowJo, LLC, Ashland, OR, USA).

Cell viability assay. Cells were seeded at a density of 8,000 cells/well in 96-well plates containing $0.1 \mathrm{ml}$ complete medium in triplicate. On the following day, cells were exposed to various concentrations of metformin and were cultured for $24 \mathrm{~h}$. Cell viability was determined using a Cell Counting kit- 8 (CCK-8; Dojindo Molecular Technologies, Inc., Shanghai, China) assay. After incubation with CCK-8 solution for $2 \mathrm{~h}$ at $37^{\circ} \mathrm{C}$, absorbance was determined at a wavelength of $450 \mathrm{~nm}$ using a SpectraMax 190 Microplate Reader (Molecular Devices, LLC, Sunnyvale, CA, USA).

Cell counting. Cell proliferation was evaluated by cell counting after cells seeded into 6 -well culture plates $\left(1 \times 10^{5}\right.$ cells/well $)$ had been incubated at $37^{\circ} \mathrm{C}$ with different treatments. The total cell number was then counted in 4 fields using a hemocytometer and the mean values were calculated from 3 replicates. The cells were counted using a phase contrast microscope (Olympus Corporation).

Transwell assay. HASMCs $\left(0.5 \times 10^{5}\right.$ cells $)$ were resuspended in $0.1 \mathrm{ml}$ serum-free SMCM and were seeded into the upper Transwell chamber ( $8 \mu \mathrm{m}$ pore size, 24-well; Corning Life Sciences, Tewksbury, MA, USA), whereas $0.8 \mathrm{ml}$ complete SMCM was used as a chemoattractant, which was added into the lower chamber. After $24 \mathrm{~h}$ at $37^{\circ} \mathrm{C}$, the cells that migrated through the membrane to the lower surface were fixed with methanol for $20 \mathrm{~min}$ and were then stained with $0.1 \%$ crystal violet solution for $20 \mathrm{~min}$. Finally, the stained cells were counted under an inverted microscope. Six random fields were chosen for analysis of cell motility.

$R N A$ extraction and reverse transcription-quantitative polymerase chain reaction ( $R T-q P C R)$. Total cellular RNA was extracted from the untreated controls, metformin-treated, control siRNA-transfected, p53 siRNA-transfected and IFI16 siRNA-transfected HASMCs using Total RNA fast extraction kit (Fastagen, Shanghai, China) according to the manufacturer's 
protocol. Total RNA $(1 \mu \mathrm{g})$ underwent cDNA synthesis using Takara PrimeScript ${ }^{\mathrm{TM}}$ RT reagent kit (Takara Bio, Inc., Otsu, Japan) according to the manufacturer's protocol. RT-qPCR was performed in a $10 \mu \mathrm{l}$ volume, using SYBR-Green PCR Master mix (Takara Bio, Inc.) on a Roche LightCycler ${ }^{\circledR} 480$ system (Roche Diagnostics GmbH, Mannheim, Germany) according to the manufacturers' protocols. Thermal cycling conditions were as follows: One cycle at $95^{\circ} \mathrm{C}$ for $10 \mathrm{~min}$, followed by 45 cycles at $95^{\circ} \mathrm{C}$ for $10 \mathrm{sec}$ and $60^{\circ} \mathrm{C}$ for $30 \mathrm{sec}$. A PCR reaction mixture was prepared. The reaction then started (stage 1 , 1 cycle at $95^{\circ} \mathrm{C}$ for $10 \mathrm{~min}$; stage 2,45 cycles at $95^{\circ} \mathrm{C}$ for $10 \mathrm{sec}$, $60^{\circ} \mathrm{C}$ for $\left.30 \mathrm{sec}\right)$. PCR amplification was conducted using the following primer sequences: p53 (239 bp), forward 5'-CTCCTCAGCATCTTATCCGAG-3', reverse 5'-GCT GTTCCGTCCCAGTAGATTA-3'; IFI16 (80 bp), forward 5'-GAAGTGCCAGCGTAACTCCTA-3', reverse 5'-TACC TCAAACACCCCATTCAC-3'; AMPK (132 bp), forward 5'-TGTGACAAGTACATACTCCAA-3', reverse 5'-GATC TCTGTGGAGTAGCAG-3'; and GAPDH (697 bp), forward 5'-TCACCATCTTCCCAGGAGCGAG-3' and reverse 5'-TGTC GCTGTTGAAGTCAGAG-3'. Relative quantification values were calculated using the $2^{-\Delta \Delta \mathrm{Cq}}$ method (28).

Western blot analysis. Whole-cell extracts were homogenized in extraction buffer (Beyotime Institure of Biotechnology). Equal amounts of lysate were separated by $8-12 \%$ SDS-PAGE and were transferred onto polyvinylidene fluoride membranes (Beyotime Institute of Biotechnology). The protein was quantified using BCA Protein Assay kit (Beyotime Institure of Biotechnology). A total of $40 \mu \mathrm{g}(4 \mu \mathrm{g} / \mu \mathrm{l} \times 10 \mu \mathrm{l})$ protein was loaded onto the gels. The membranes were blocked with $5 \%$ nonfat dry milk and were then incubated with the recommended concentration of primary antibody overnight at $4^{\circ} \mathrm{C}$. The membranes (needless primary antibodies) were washed three times (15 $\mathrm{min} / \mathrm{wash})$ and were then incubated with a 1:5,000-1:10,000 dilution of peroxidase-conjugated goat anti-rabbit (1:10,000; cat. no. 9101) and goat anti-mouse (1:10,000; cat. no. 9100) secondary antibodies (OriGene Technologies, Inc., Beijing, China) for $1 \mathrm{~h}$ at room temperature. Finally, the membranes (needless secondary antibodies) were washed three times (15 min/wash). Blots were visualized using an enhanced chemiluminescence buffer and an Amersham Imager 600 (GE Healthcare, Chicago, IL, USA). The data were analyzed with ImageJ software v2.1.4.7 (National Institutes of Health, Bethesda, MD USA). Each experiment was repeated three times to ensure consistency of the results. The primary antibodies used in the present study were as follows: Rabbit anti-human AMPK $\alpha$ monoclonal antibody (1:1,000; cat. no. 2603), rabbit anti-human phosphorylated (p)-AMPK $\alpha$ (Thr-172) monoclonal antibody (1:1,000; cat. no. 2535) (both Cell Signaling Technology, Inc., Danvers, MA, USA), mouse anti-human IFI16 monoclonal antibody (1:200; cat. no. sc-8023), rabbit anti-human GAPDH polyclonal antibody (1:200; cat. no. sc-25778) (both Santa Cruz Biotechnology, Inc.), rabbit anti-human p53 polyclonal antibody (1:1,000; cat. no. 10442-1-AP; Proteintech Group, Inc., Chicago, IL, USA), rabbit anti-human p-p53 (Ser-15) antibody (1:1,000; cat. no. 9284), rabbit anti-human ATM monoclonal antibody (1:1,000; cat. no. 2873) and mouse anti-human p-ATM (Ser-1981) monoclonal antibody (1:1,000; cat. no. 4526) (all Cell Signaling Technology, Inc.).
Immunofluorescence. Following the appropriate treatment in 24-well plates, the cells were washed three times with PBS and were fixed with $4 \%$ paraformaldehyde for $15 \mathrm{~min}$ at room temperature. The cells were washed a further three times with PBS and were permeabilized with $0.5 \%$ Triton X-100 for $20 \mathrm{~min}$ at room temperature, prior to three further washes with PBS and blocking with 30\% goat serum (Beyotime Institure of Biotechnology) for $30 \mathrm{~min}$ at room temperature. The cells were incubated with the recommended concentration of primary antibodies [rabbit polyclonal anti-human P53 (1: 200; cat. no. 10442-1-AP; Proteintech Group, Inc.) and mouse monoclonal anti-human IFI16 (1: 50; cat. no. sc-8023; Santa Cruz Biotechnology, Inc.)] overnight at $4^{\circ} \mathrm{C}$. Subsequently, the cells were washed three times with PBS and were incubated with fluorescein isothiocyanate (FITC) (green)-conjugated goat anti-rabbit (1:50; cat. no. 0311), and rhodamine (red)-conjugated goat anti-mouse (1:50; cat. no. 0313) secondary antibodies (both from OriGene Technologies, Inc.) at $37^{\circ} \mathrm{C}$ for $1 \mathrm{~h}$. After washing three times, the nuclei (blue) were counterstained with DAPI for $5 \mathrm{~min}$. The cells were observed under an inverted fluorescence microscope (Olympus Corporation) with appropriate optical filters. At least six randomly selected fields were examined in each of the three separate experiments. The ratio $=($ number of stained cells/number of total cells $\times 100 \%$

Statistical analysis. Data are presented as the means \pm standard deviation from at least three independent experiments. Comparisons between two or more groups were subjected to a two-tailed Student's t-test or ANOVA when appropriate. All statistical analyses were performed using SPSS 17.0 statistical software (SPSS, Inc., Chicago, IL, USA) and GraphPad Prism 5 software (GraphPad Software, Inc., La Jolla, CA, USA). P<0.05 was considered to indicate a statistically significant difference.

\section{Results}

Senescent primary HASMCs exhibit a decrease in proliferation and migration. To determine the proliferative and migratory capabilities of HASMCs, HASMCs were investigated at different passage numbers. Pre-senescent HASMCs (passage number 3; young) exhibited a small and spindle-like morphology, whereas post-senescent HASMCs (passage number 7; old) appeared morphologically flattened with enlarged shapes; these cells were more positive for the recognized biomarker of senescence (SA- $\beta$-gal) (Fig. 1A and B). After cell counting, the present study indicated that the number of old cells was significantly lower compared with the number of young cells after the first 24-h culture (Fig. 1C). In addition, the viability of senescent HASMCs was markedly decreased after a 24-h culture, according to the results of the CCK-8 assay (Fig. 1D). As shown in Fig. 1E and F, the proportion of cells arrested at $G_{1}$ phase of the cell cycle was evidently increased, and the percentage of cells at $\mathrm{S}$ phase was markedly decreased among the old cells compared with the young cells. The results of a cell migration assay indicated that the migratory capabilities of the old cells were markedly reduced compared with the young cells (Fig. $1 \mathrm{G}$ and $\mathrm{H}$ ).

Protein expression levels of p53, IFI16, AMPK and p-AMPK are increased in old HASMCs. The present study aimed to detect the relative expression levels of proteins associated with growth 


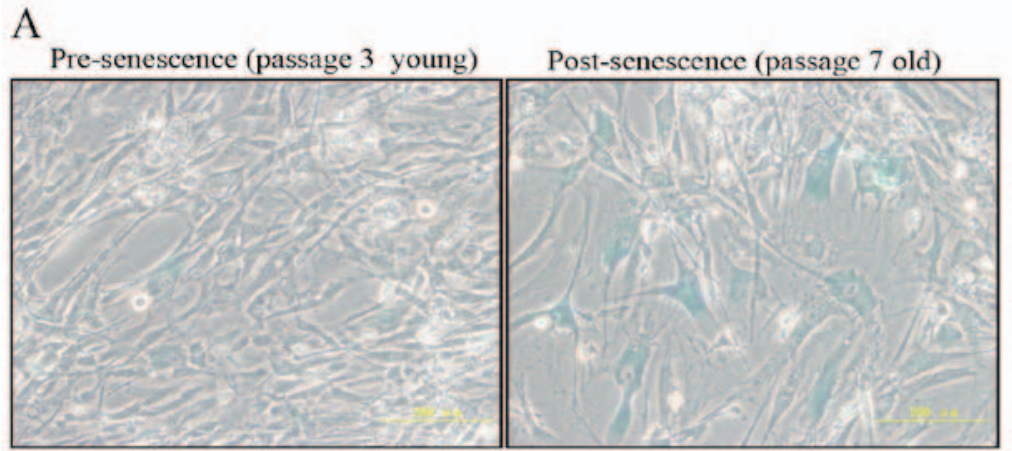

B

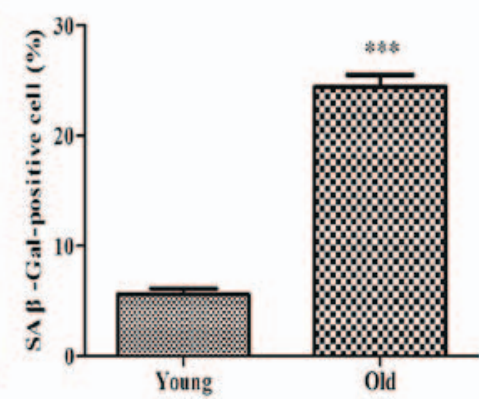

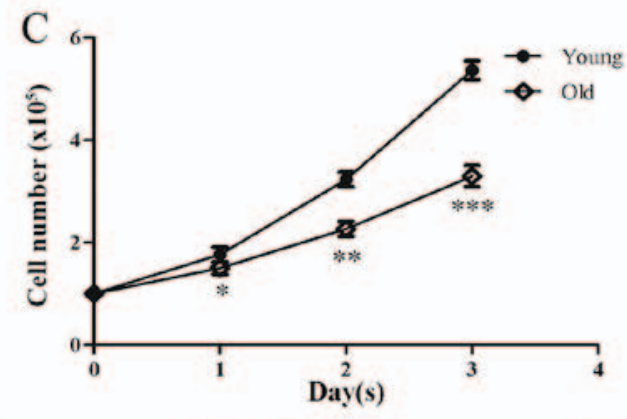

E

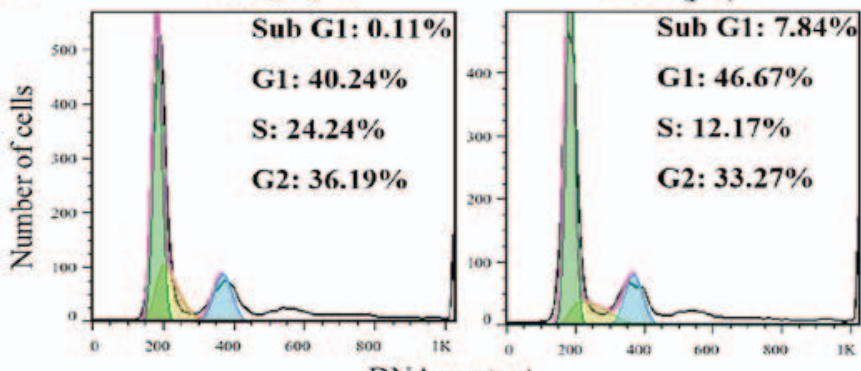

DNA content

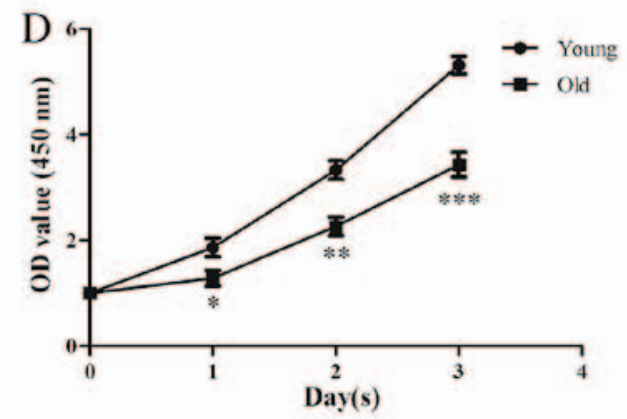

$\mathrm{F}$

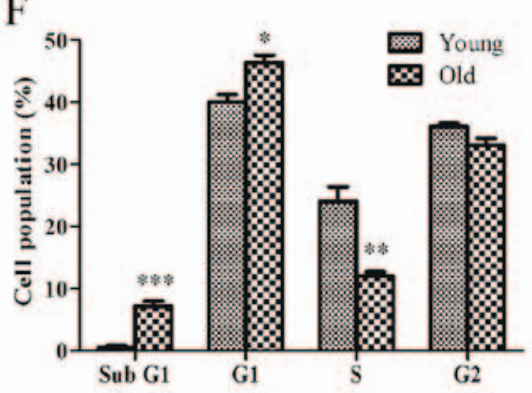

$\mathrm{H}$

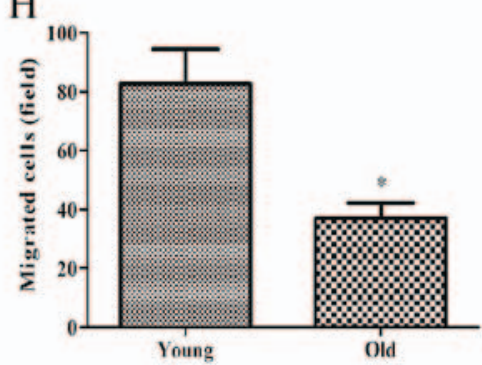

Figure 1. Senescent primary HASMCs exhibit a decrease in proliferation and migration. Young (passage number 3) and old (passage number 7) cells were seeded at a density of $1 \times 10^{5}$ cells/well in 6-well culture plates (SA- $\beta$-gal staining assay, cell counting assay, CCK- 8 assay and cell cycle assay). (A) SA- $\beta$-gal activity was detected using a SA- $\beta$-gal staining assay following culturing for 3 days. Blue cells were considered SA- $\beta$-gal-positive cells. (B) Histogram represents the percentage of SA- $\beta$-gal-positive cells. (C) Number of cells was counted per well after 0, 1, 2 and 3 days. (D) Cell viability was detected using the Cell Counting kit-8 assay after $0,1,2$ and 3 days. (E) Cell cycle progression was detected using a cell cycle assay following culturing for 3 days. (F) Histogram represents the percentage of cells in each cell cycle phase. (G) After culturing for 3 days, equal numbers of young and old cells $\left(0.5 \times 10^{5}\right)$ were seeded into the upper Transwell chambers and were cultured for $24 \mathrm{~h}$. Representative images of stained and migrated cells are presented; magnification, $\mathrm{x} 200$. (H) Number of migrated cells was quantified by counting the cells from six random fields. All data are presented as the means \pm standard deviation from three independent experiments. ${ }^{*} \mathrm{P}<0.05,{ }^{* *} \mathrm{P}<0.01$ and ${ }^{* * * *} \mathrm{P}<0.001$ vs. the young group. HASMCs, human aortic smooth muscle cells; OD, optical density; SA- $\beta$-gal, senescence-associated $\beta$-galactosidase.

arrest and migratory inhibition in senescent HASMCs. As shown in Fig. 2A and B, the basal levels of p53, IFI16, AMPK and p-AMPK were higher in the protein extracts derived from old HASMCs compared with in those derived from young HASMCs. Immunofluorescence analysis indicated that endogenous p53 expression (green) was increased in the old cells compared with in the young cells (Fig. 2C and D). In addition, the expression levels of endogenous IFI16 (red) were increased in old HASMCs (Fig. 2E and F).
Metformin upregulates p53, IFI16 and p-AMPK expression, and inhibits proliferation and migration of HASMCs. To explore whether the suppressive effects of metformin were associated with the extent of relative protein activation in HASMCs, a dose-dependent immunoblot analysis was conducted. HASMCs (passage 3 ) were treated with various concentrations of metformin (0-10 mmol/l) for $24 \mathrm{~h}$. As shown in Fig. 3A, the mRNA expression levels of p53 and IFI16 were increased in a 
A

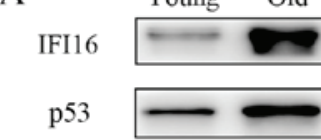

AMPK

p-AMPK

GAPDH
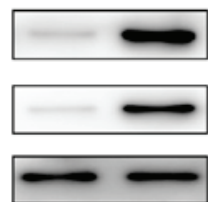

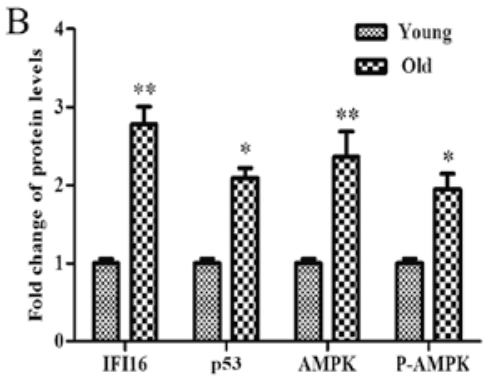

$\mathrm{D}$
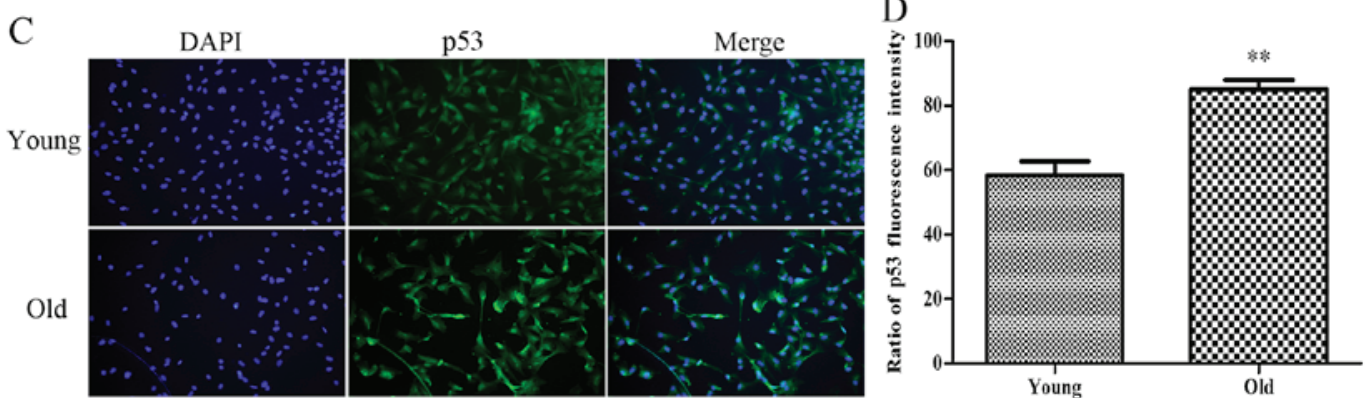

Old

E

DAPI
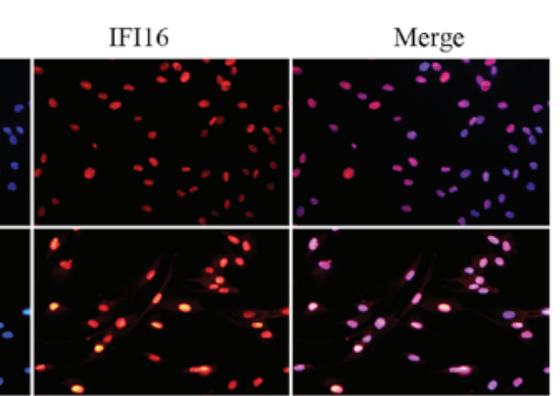

$\mathrm{F}$
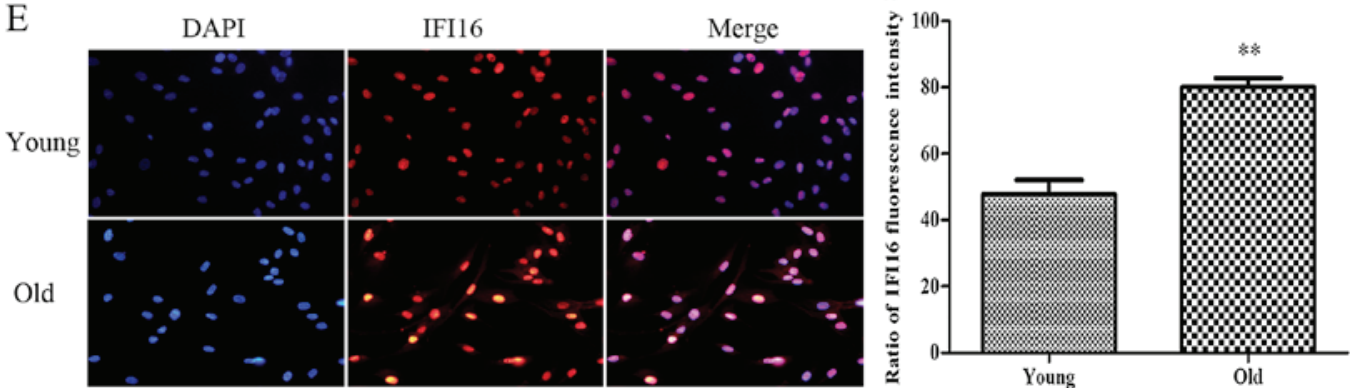

Figure 2. Protein expression levels of p53, IFI16, AMPK and p-AMPK are increased in old (passage 7) HASMCs compared with in young (passage 3) HASMCs. Young and old cells were cultured for 3 days. (A) Western blot analysis was used to detect IFI16, p53, AMPK and p-AMPK expression in young and old HASMCs. GAPDH was used as a loading control. (B) Histogram represents the fold change in IFI16, p53, AMPK and p-AMPK protein expression normalized to GAPDH relative to the young group. (C) Young and old cells were stained with a fluorescein isothiocyanate (green)-conjugated secondary antibody to detect endogenous p53 and nuclei were stained with DAPI (blue). Cells were observed under a fluorescence microscope (magnification, x100). (D) Histogram represents the percentage of endogenous p53-positive cells. (E) Young and old cells were stained with a rhodamine (red)-conjugated secondary antibody to detect endogenous IFI16 and nuclei were stained with DAPI (blue). Cells were observed under a fluorescence microscope (magnification, x200). (F) Histogram represents the percentage of endogenous IFI16-positive cells. All data are presented as the means \pm standard deviation from three independent experiments. ${ }^{*} \mathrm{P}<0.05$ and ${ }^{* *} \mathrm{P}<0.01$ vs. the young group. AMPK, 5 ' adenosine monophosphate-activated protein kinase; HASMCs, human aortic smooth muscle cells; IFI16, interferon-inducible protein 16; p-AMPK, phosphorylated-AMPK.

A

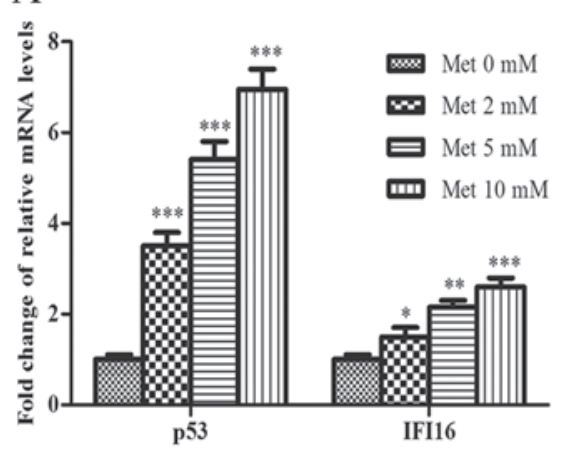

B Metformin

p53

p-p53(Ser-15)

IFI16

AMPK

p-AMPK

GAPDH
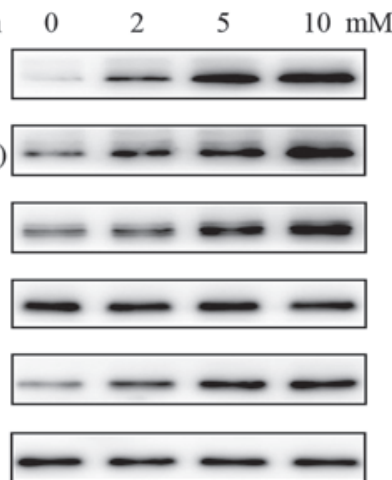

$\mathrm{C}$

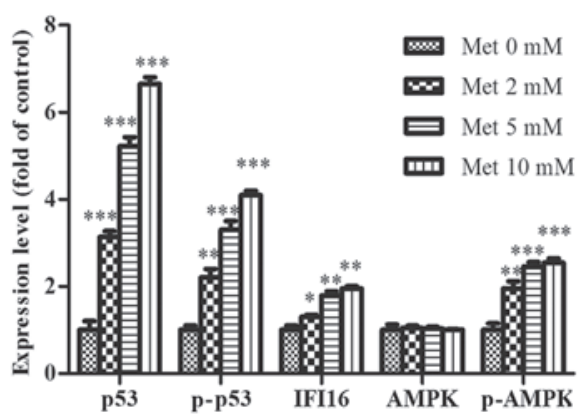

Figure 3. Met activates p53, p-p53, IFI16 and p-AMPK in HASMCs (passage 3). HASMCs were treated with Met at various concentrations $(0,2,5$ and $10 \mathrm{mmol} / \mathrm{l}$ ) for $24 \mathrm{~h}$. (A) mRNA expression levels of p53 and IFI16 were measured by reverse transcription-quantitative polymerase chain reaction. Histogram represents the fold change in p53 and IFI16 mRNA expression normalized to GAPDH relative to the control (met $0 \mathrm{mM}$ ). (B) Western blotting was performed to detect p53, p-p53, IFI16, AMPK and p-AMPK protein expression. GAPDH was used as a loading control. (C) Histogram represents the fold change in p53, p-p53, IFI16, AMPK and p-AMPK protein expression normalized to GAPDH relative to the control (met $0 \mathrm{mM})$. All data are presented as the means \pm standard deviation of three independent experiments. ${ }^{*} \mathrm{P}<0.05,{ }^{* *} \mathrm{P}<0.01$ and $^{* * * *} \mathrm{P}<0.001$ vs. the control group. AMPK, 5 ' adenosine monophosphate-activated protein kinase; HASMCs, human aortic smooth muscle cells; IFI16, interferon-inducible protein 16; Met, metformin; p-, phosphorylated. 

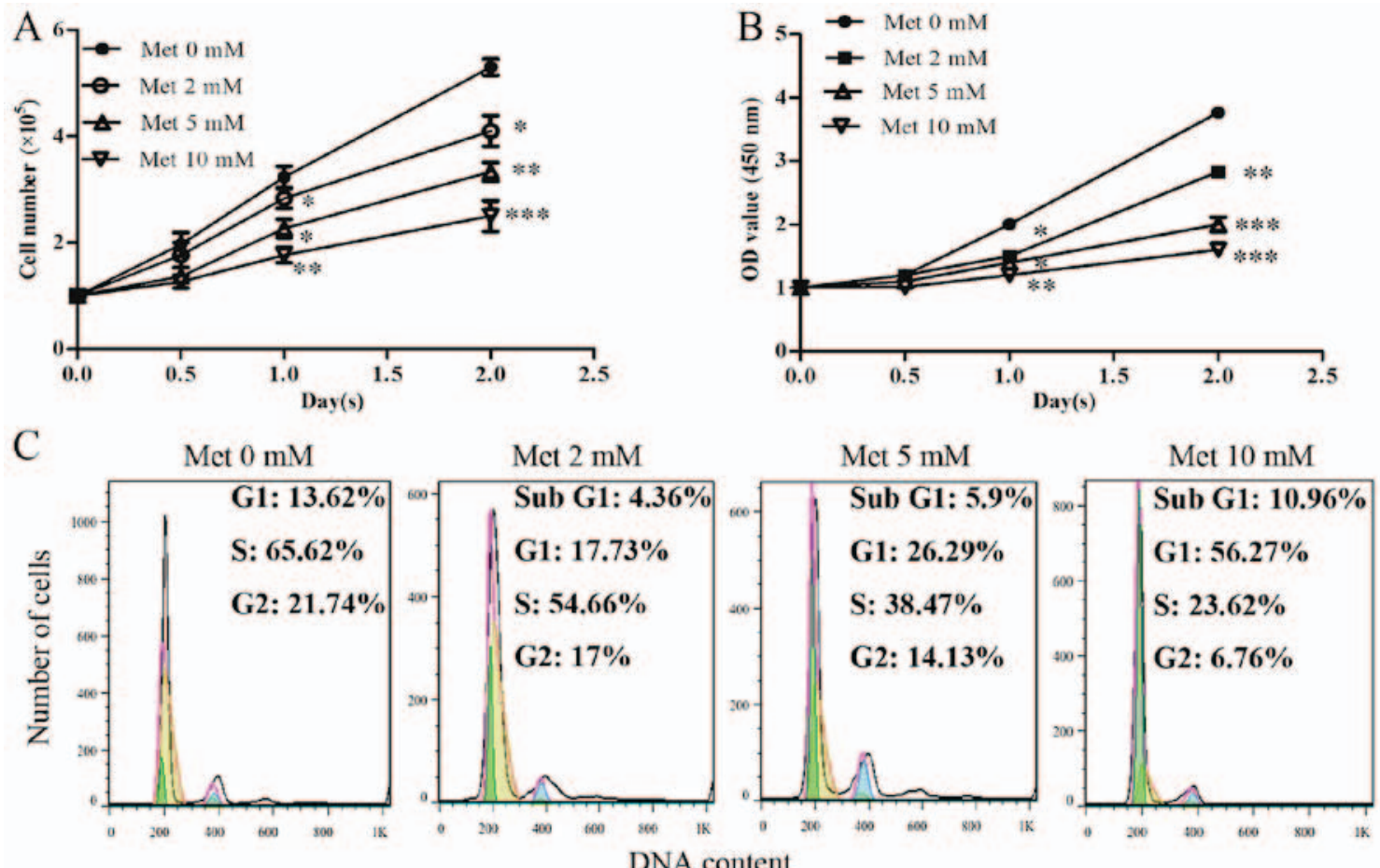

D $\quad$ Met $0 \mathrm{mM}$

DNA content
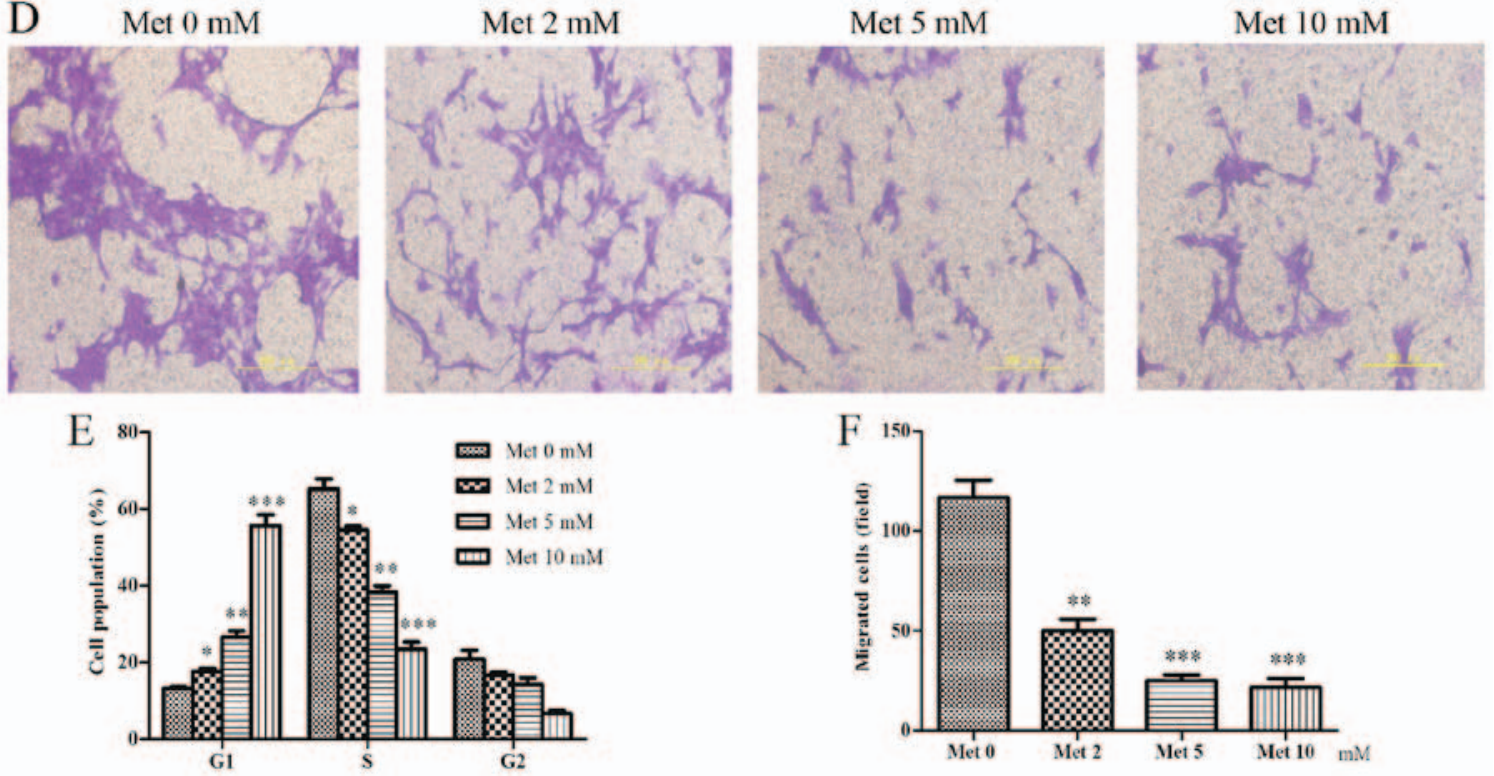

Figure 4. Met inhibits the proliferation and migration of HASMCs (passage 3). HASMCs were seeded at a density of 1x105 cells/well in 6-well culture plates (cell counting assay, CCK-8 assay and cell cycle assay) and were treated with Met at various concentrations $(0,2,5$ and $10 \mathrm{mmol} / \mathrm{l})$ for $0,0.5,1.0$ and 2.0 day (A) Cell number per well was counted following treatment with various concentrations of Met for 0, 0.5, 1.0 and 2.0 days. (B) Cell viability was determined using the Cell Counting kit- 8 assay following treatment with various concentrations of Met for 0, 0.5, 1.0 and 2.0 days. (C and E) Cell cycle progression was determined using a cell cycle assay following treatment with various concentrations of Met for $24 \mathrm{~h}$. Histogram represents the percentage of cells in each cell cycle phase. (D and F) Cell migration was detected by Transwell assay following treatment with various concentrations of Met for $24 \mathrm{~h}$. Representative images of stained and migrated cells are shown; magnification, x200. Histogram represents the number of migrated cells from six random fields. All data are presented as the means \pm standard deviation from three independent experiments. ${ }^{*} \mathrm{P}<0.05,{ }^{* *} \mathrm{P}<0.01$ and ${ }^{* * * *} \mathrm{P}<0.001$ vs. the control group (Met 0 mM). HASMCs, human aortic smooth muscle cells; Met, metformin; OD, optical density.

dose-dependent manner following treatment with metformin. The protein expression levels of p53, p-p53 (Ser-15), IFI16 and p-AMPK (Thr-172) were also steadily increased in response to increasing metformin concentrations (Fig. 3B and C).

As shown in Fig. 4A and B, incubation of the cells with increasing metformin concentrations resulted in an inhibition in cell growth and reduced cell viability. Similar to the effects of senescence on cell cycle progression, metformin was able to arrest HASMCs in $\mathrm{G}_{1}$ phase and decreased the percentage of cells in S phase of the cell cycle in a dose-dependent manner (Fig. 4C and E). Furthermore, increasing metformin concentrations resulted in a gradual, significant reduction in the migration of HASMCs (Fig. 4D and F).

p53-knockdown significantly suppresses metformin-mediated growth arrest and migratory inhibition in HASMCs. To 

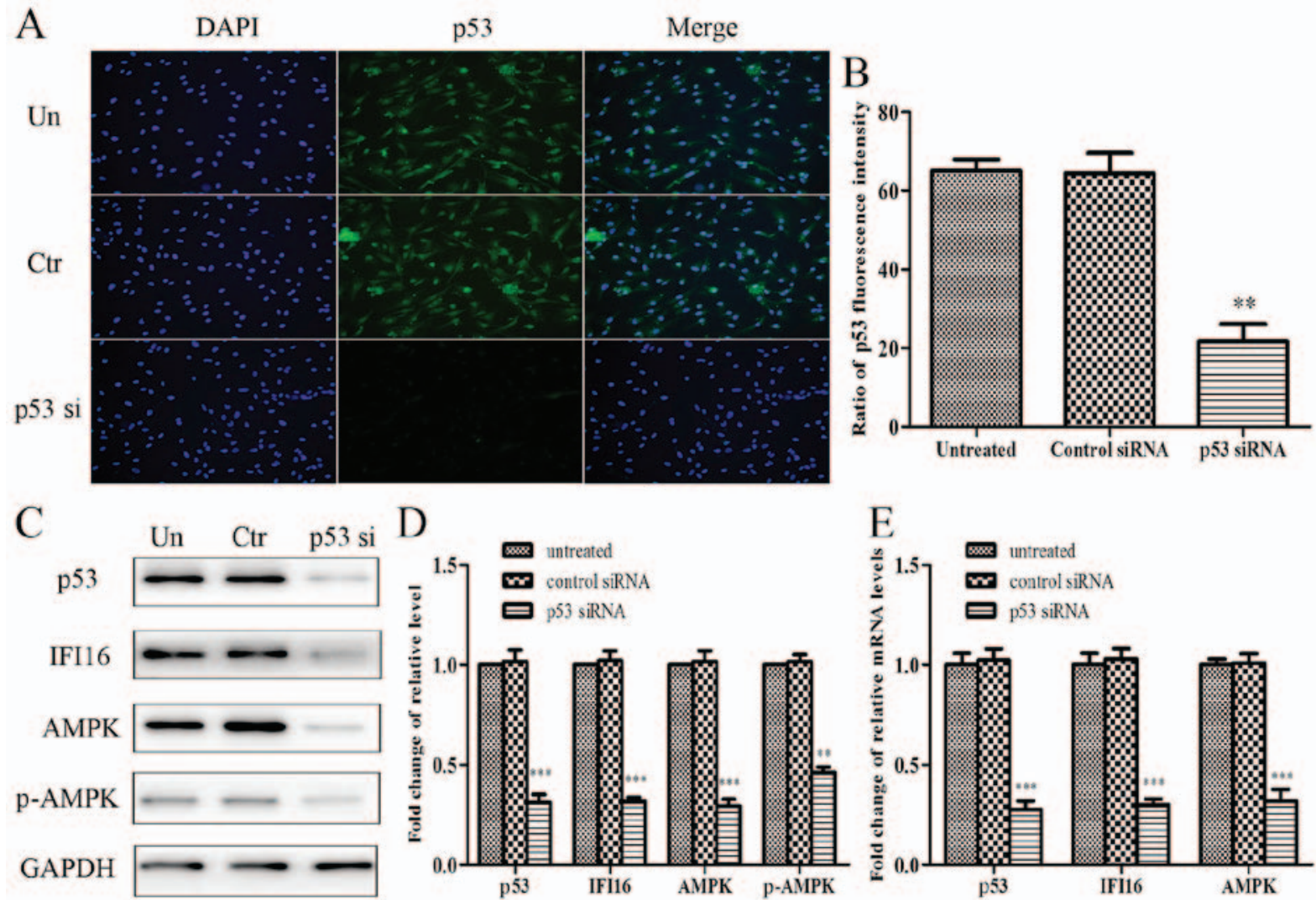

Figure 5. Effects of p53-knockdown on the protein and mRNA expression levels of IFI16, AMPK and p-AMPK in HAMSCs (passage 3). HASMCs were untreated, or were transfected with control siRNA or p53 siRNA. (A) A total of $48 \mathrm{~h}$ post-transfection, immunofluorescence analysis was performed to detect endogenous p53 expression. (B) Histogram represents the ratio of p53 fluorescence intensity from six random fields. (C) A total of 48 h post-transfection, cells were lysed and examined by western blotting to detect p53, IFI16, AMPK and p-AMPK protein expression. (D) Histogram represents the fold change in p53, IFI16, AMPK and p-AMPK protein expression normalized to GAPDH relative to the untreated group. (E) A total of $24 \mathrm{~h}$ post-transfection, the mRNA expression levels of p53, IFI16 and AMPK were measured by reverse transcription-quantitative polymerase chain reaction. Histogram represents the fold change in p53, IFI16 and AMPK mRNA expression normalized to GAPDH relative to the untreated group. All data are presented as the means \pm standard deviation from three independent experiments. ${ }^{* *} \mathrm{P}<0.01$ and ${ }^{* * *} \mathrm{P}<0.001$ vs. the untreated group. AMPK, 5' adenosine monophosphate-activated protein kinase; Ctr, control; HASMCs, human aortic smooth muscle cells; IFI16, interferon-inducible protein 16; p-, phosphorylated; siRNA, small interfering RNA; Un, untreated.

explore the role of $\mathrm{p} 53$ in metformin-mediated growth arrest and migratory inhibition, p53 was knocked down using p53 siRNA, and the effects of metformin on 53 -silenced HASMCs were reassessed. The present study initially confirmed that p53 was knocked down in p53 siRNA-transfected HASMCs. Cell immunofluorescence analysis indicated that endogenous p53 expression was evidently attenuated in cells transfected with p53 siRNA (Fig. 5A and B). Furthermore, p53-knockdown resulted in a significant reduction in the expression levels of IFI16, AMPK and p-AMPK (Fig. 5C and D). With regards to mRNA expression, p53, IFI16 and AMPK expression was significantly reduced in p53 siRNA-transfected cells (Fig. 5E).

A total of 24 hours after culture, the results indicated that p53-silenced cells exhibited increased proliferation, which was resistant to metformin-induced growth arrest (Fig. 6A). Analysis of cell cycle progression indicated that the percentage of $\mathrm{G}_{1}$ phase cells was significantly decreased and the percentage of S phase cells was increased in p53-silenced HASMCs. Notably, p53-knockdown evidently suppressed the metformin-mediated increase in the accumulation of HASMCs in $G_{1}$ phase of the cell cycle (Fig. 6B and C). Furthermore, cell viability was markedly increased in the p53-silenced cells, whereas the metformin-mediated decrease in cell viability was suppressed by knockdown of p53 (Fig. 6D). Cell migration analysis indicated that knockdown of p53 promoted an increase in mobility. As expected, metformin-induced migratory inhibition was markedly suppressed in HASMCs when cells were transfected with p53 siRNA prior to metformin-treatment (Fig. 6E and F).

IFI16-knockdown significantly suppresses metformin-mediated growth arrest and migratory inhibition in HASMCs. Subsequently, the present study aimed to investigate the role of IFI16 in metformin-mediated suppressive effects. IFI16 siRNA significantly attenuated endogenous IFI16 expression, thus confirming that IFI16 was knocked down in HASMCs transfected with IFI16 siRNA (Fig. 7A and B). Furthermore, downregulation of IFI16 markedly decreased the expression levels of AMPK and p-AMPK; however, the expression levels of p53 were not significantly altered in response to IFI16 siRNA (Fig. 7C and D). Similarly, the mRNA expression levels of IFI16 and AMPK were decreased in IFI16 siRNA-transfected cells. IFI16 siRNA had no significant effect on p53 mRNA expression (Fig. 7E).

Through cell counting, cell cycle assay and CCK- 8 assay, the present study demonstrated that IFI16-silenced cells exhibited increased proliferation compared with the control 

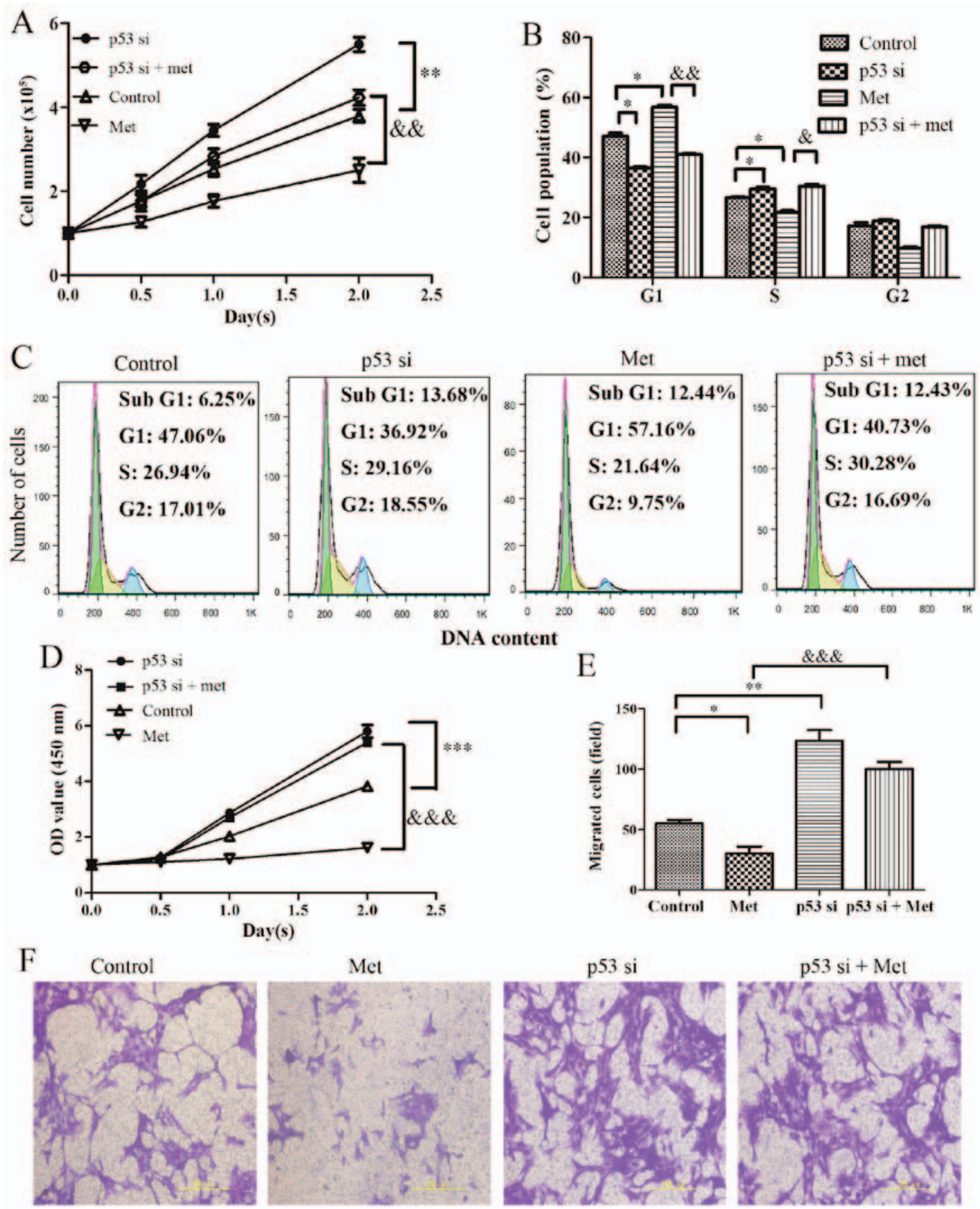

Figure 6. Effects of p53-knockdown on Met-mediated growth arrest and migratory inhibition in HASMCs (passage 3). Control HASMCs and p53-silenced HASMCs ( $48 \mathrm{~h}$ post-transfection) were treated with or without $10 \mathrm{mM}$ metformin for $24 \mathrm{~h}$. (A) Control HASMCs (Control), p53-silenced HASMCs (p53 si), control HASMCs treated with Met (Met) and p53-silenced HASMCs treated with Met (p53 si + Met) were seeded at a density of 1x10 5 cells/well in 6-well culture plates (cell counting assay, CCK-8 assay and cell cycle assay). Number of cells per well was counted at 0, 0.5, 1.0 and 2.0 days. (B and C) Cell cycle analysis was performed to evaluate the number of cells in each phase of the cell cycle in each group. Histogram represents the percentage of cells in each cell cycle phase. (D) Cell viability was detected using the Cell Counting kit-8 assay at $0,0.5,1.0$ and 2.0 days. (E and F) Cell migration was detected by Transwell assay in each group. Representative images of stained and migrated cells are shown; magnification, x200. Histogram represents the number of migratory cells per field from six random fields. All data are presented as the means \pm standard deviation from three independent experiments. ${ }^{*} \mathrm{P}<0.05,{ }^{* * *} \mathrm{P}<0.01$ and ${ }^{* * * *} \mathrm{P}<0.001$ vs. the control group; ${ }^{\text {\& }} \mathrm{P}<0.05$, \&\& $\mathrm{P}<0.01$ and ${ }^{\& \& \&} \mathrm{P}<0.001$ vs. the Met group. HASMCs, human aortic smooth muscle cells; Met, metformin; OD, optical density; si, small interfering RNA.

cells. Notably, IFI16-knockdown markedly suppressed metformin-induced cell growth inhibition, $\mathrm{G}_{1}$ phase cell cycle arrest and cell viability inhibition (Fig. 8A-D). In addition, IFI16 siRNA transfection induced an increase in cell migration. As expected, metformin hardly had an effect on the migration of IFI16-silenced cells (Fig. 8E and F).
Metformin upregulates IFI16 and p-AMPK expression through activating p53 in HASMCs. To investigate the molecular mechanism underlying p53-knockdown-induced suppression of metformin-mediated growth arrest and migratory inhibition, HASMCs were transfected with p53 siRNA followed by metformin stimulation for $24 \mathrm{~h}$. Western blot 

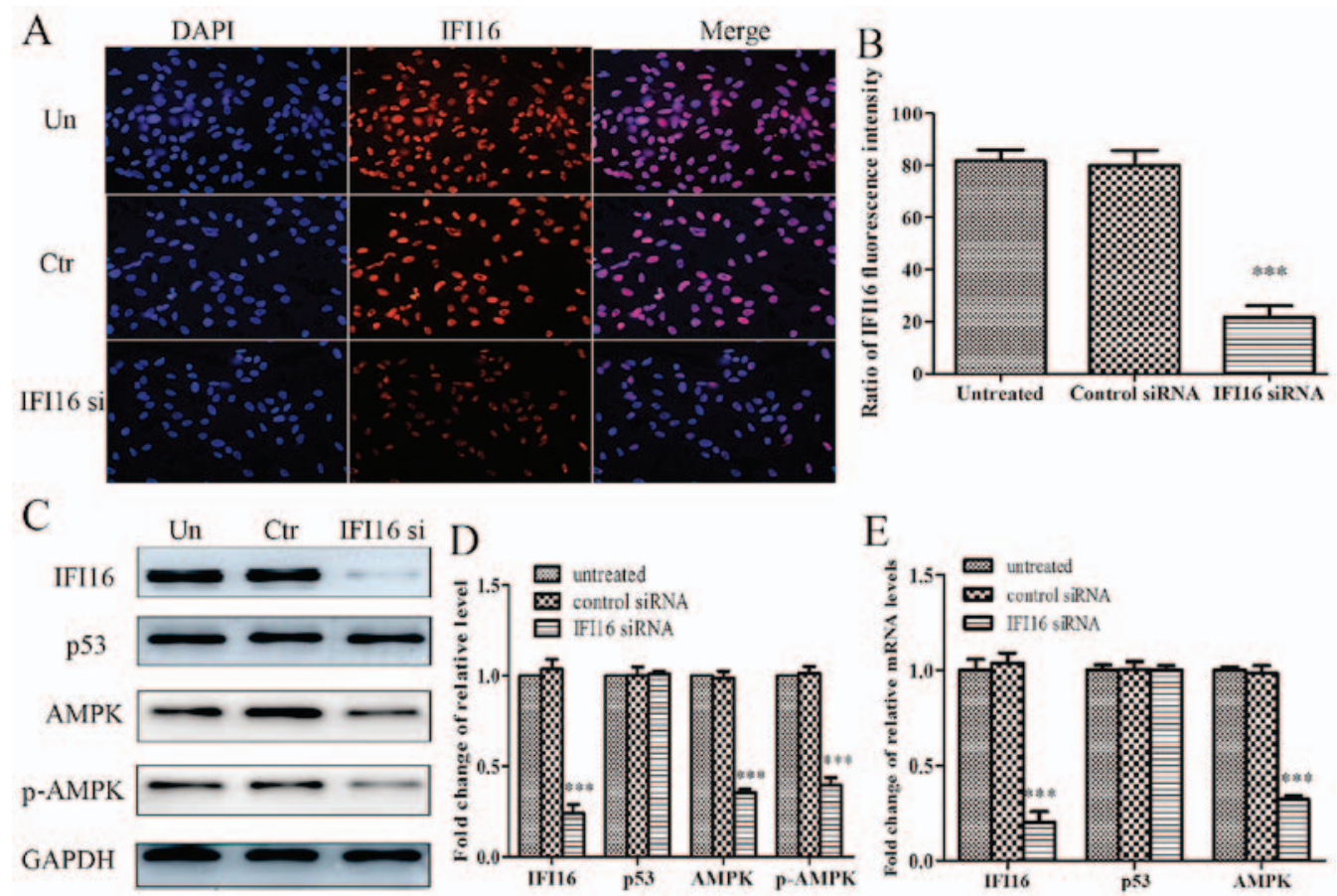

Figure 7. Effects of IFI16-knockdown on the protein and mRNA expression levels of p53, AMPK and p-AMPK in HAMSCs (passage 3). HASMCs were untreated, or were transfected with control siRNA or IFI16 siRNA. (A) A total of $48 \mathrm{~h}$ post-transfection, immunofluorescence analysis was performed to detect endogenous IFI16 expression. (B) Histogram represents the ratio of IFI16 fluorescence intensity from six random fields. (C) A total of $48 \mathrm{~h}$ post-transfection, cells were lysed and examined by western blotting to detect IFI16, p53, AMPK and p-AMPK protein expression. (D) Histogram represents the fold change in IFI16, p53, AMPK and p-AMPK protein expression normalized to GAPDH relative to the untreated group. (E) A total of $24 \mathrm{~h}$ post-transfection, the mRNA expression levels of IFI16, p53 and AMPK were measured by reverse transcription-quantitative polymerase chain reaction. Histogram represents the fold change in IFI16, p53 and AMPK mRNA expression normalized to GAPDH relative to the untreated group. All data are presented as the means \pm standard deviation from three independent experiments. ${ }^{* * *} \mathrm{P}<0.001$ vs. the untreated group. AMPK, 5' adenosine monophosphate-activated protein kinase; Ctr, control; HASMCs, human aortic smooth muscle cells; IFI16, interferon-inducible protein 16; p-, phosphorylated; siRNA, small interfering RNA; Un, untreated.

analysis indicated that metformin upregulated ATM, p-ATM (Ser-1981), p53, p-p53 (Ser-15), IFI16 and p-AMPK expression in p53 siRNA-untreated cells; however, metformin had no significant effect on IFI16 and p-AMPK expression in p53-silenced cells. Conversely, metformin was able to potentiate ATM and p-ATM expression in p53-silenced cells (Fig. 9).

IFI16 is required for metformin-induced upregulation of $p$-AMPK. In order to investigate the molecular mechanism underlying IFI16-knockdown-induced suppression of metformin-mediated suppressive effects, HASMCs were transfected with IFI16 siRNA followed by metformin stimulation for $24 \mathrm{~h}$. Western blot analysis indicated that, although p53 expression was increased in IFI16-silenced cells in response to metformin, IFI16-knockdown markedly suppressed the metformin-induced increase in p-AMPK expression (Fig. 10).

\section{Discussion}

Previous studies have suggested that metformin exerts significant cardioprotective effects alongside its fundamental role as an antidiabetic agent $(10,11)$. The mechanism of action of metformin in atherosclerosis is associated with AMPK (29,30). It has previously been reported that numerous cytokines, chemokines and growth factors regulate smooth muscle cell proliferation and the progression of atheroscle- rosis $(31,32)$. Increased proliferation of smooth muscle cells has been observed during early atherosclerosis (1). Smooth muscle cell migration into the intima is considered evidence that smooth muscle cell migration from the media is important in atherogenesis (4).

Activation of AMPK by metformin antagonizes the proliferation and migration of HASMCs (14). Consistent with the results of the present study, treatment with metformin can significantly inhibit the growth and migration of HASMCs via activation of AMPK.

Previous studies have reported that AMPK and p53 serve important roles in metformin-mediated cell growth arrest and migratory inhibition $(21,22,33)$. The present study indicated that p53-knockdown resulted in downregulation of IFI16, AMPK and p-AMPK. Furthermore, metformin has been reported to activate p53 via ATM, in order to upregulate IFI16 and p-AMPK; however, in the present study, metformin had no significant effect on activation of IFI16 and p-AMPK in p53-silenced HASMCs. These findings suggested that p53 is required for metformin-mediated activation of IFI16 and AMPK, and is essential for metformin-mediated suppressive effects in HASMCs.

The present study further examined whether metformin-mediated growth arrest and migratory inhibition of HASMCs in an IFI16-dependent manner. IFI16 siRNA had no significant effects on p53 expression, whereas it decreased the levels of AMPK and p-AMPK. Furthermore, metformin had no significant effects on antagonizing 

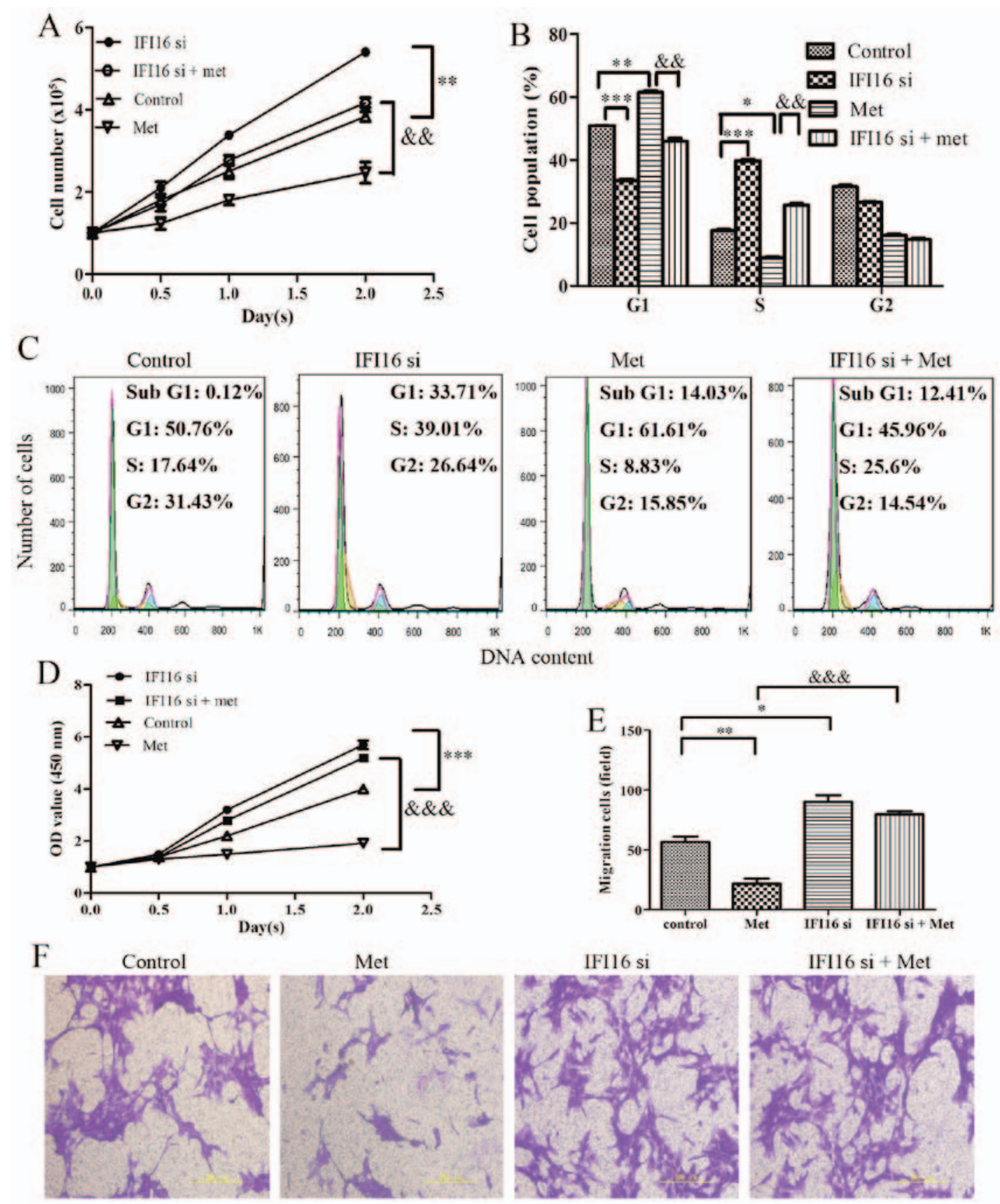

Figure 8. Effects of IFI16-knockdown on Met-mediated growth arrest and migratory inhibition in HASMCs (passage 3). Control HASMCs and IFI16-silenced HASMCs ( $48 \mathrm{~h}$ post-transfection) were untreated or treated with $10 \mathrm{mM}$ of Met for $24 \mathrm{~h}$. (A) Control HASMCs (control), IFI16-silenced HASMCs (IFI16 si), control HASMCs treated with Met (Met) and IFI16-silenced HASMCs treated with Met (IFI16 si + Met) were seeded at a density of 1x105 cells/well in 6-well culture plates (cell counting assay, CCK-8 assay and cell cycle assay). Number of cells per well was counted at 0, 0.5, 1.0 and 2.0 days. (B and C) Cell cycle analysis was performed to evaluate the number of cells in each phase of the cell cycle in each group. Histogram represents the percentage of cells in each cell cycle phase. (D) Cell viability was detected using the Cell Counting kit-8 assay at 0, 0.5, 1.0 and 2.0 days. (E and F) Cell migration was detected using a Transwell assay in each group. Representative images of stained and migrated cells are shown; magnification, x200. Histogram represents the number of migratory cells per field from six random fields. All data are presented as the means \pm standard deviation from three independent experiments. ${ }^{*} \mathrm{P}<0.05$, ${ }^{* *} \mathrm{P}<0.01$ and ${ }^{* * *} \mathrm{P}<0.001$ vs. the control group; ${ }^{\&} \mathrm{P}<0.01$ and ${ }^{\& \&} \& \mathrm{P}<0.001$ vs. the Met group. HASMCs, human aortic smooth muscle cells; IFI16, interferoninducible protein 16; Met, metformin; OD, optical density; si, small interfering RNA.

cell proliferation and migration, and activating AMPK in IFI16-silenced HASMC. These results indicated that the metformin-induced upregulation of p53 may activate AMPK in an IFI16-dependent manner, and IFI16 may be required for metformin-mediated inhibition of HASMC proliferation and migration. Notably, IFI16 has been reported to serve a central role in suppressing cell proliferation (34). Therefore, in the present study, it was also hypothesized that the antiproliferative and antimigratory effects of metformin may be attributed to IFI16 activation. The present study demonstrated that metformin inhibits cell proliferation and migration of primary HASMCs via upregulation of p53 and IFI16. To the best of our knowledge, the present study is the first, to the best of our knowledge, to demonstrate that activation of AMPK by metformin antagonizes proliferation and migration, and these activities require the participation of 
A $\quad \begin{array}{lllll}\text { Met } & - & + & - & + \\ \text { p53 si } & - & - & + & +\end{array}$

ATM

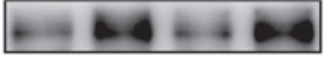

p-ATM (Ser-1981) $\square \ldots \ldots$

p53 $\longrightarrow-\infty$

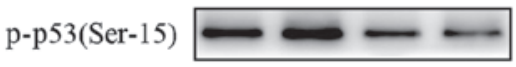

GAPDH

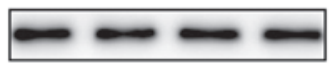

Met - $+\quad+$

p53 si - - $\quad+\quad+$

IFI16

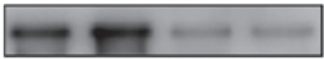

AMPK

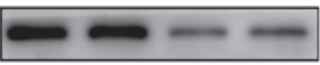

p-AMPK

GAPDH

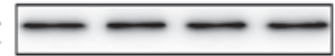

B
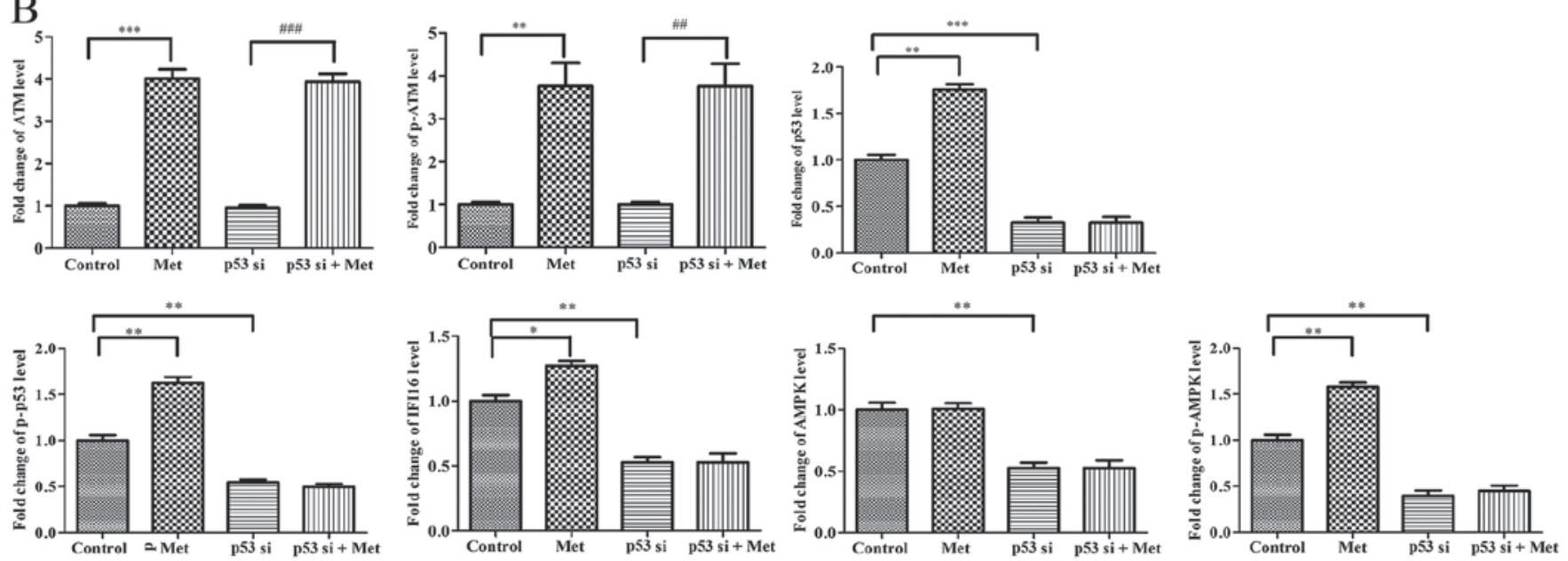

Figure 9. Met does not activate IFI16 and AMPK in p53-silenced HASMCs. Control HASMCs and p53-silenced HASMCs (48 h post-transfection) were treated with or without $10 \mathrm{mM}$ Met for 24 h. (A) Control HASMCs (control), control HASMCs treated with Met (Met), p53-silenced HASMCs (p53 si) and p53silenced HASMCs treated with Met (p53 si + Met) were lysed and examined by western blot analysis to detect ATM, p-ATM, p53, p-p53, IFI16, AMPK and p-AMPK protein expression. (B) Histogram represents fold change in protein expression normalized to GAPDH relative to the control. All data are presented as the means \pm standard deviation from three independent experiments. ${ }^{*} \mathrm{P}<0.05,{ }^{* * *} \mathrm{P}<0.01$ and ${ }^{* * * *} \mathrm{P}<0.001$ vs. the control group; ${ }^{\# \#} \mathrm{P}<0.01$ and ${ }^{\# \# \#} \mathrm{P}<0.001$ vs. the p53 si group. AMPK, 5' adenosine monophosphate-activated protein kinase; ATM, ataxia telangiectasia-mutated; HASMCs, human aortic smooth muscle cells; IFI16, interferon-inducible protein 16; p-, phosphorylated; si, small interfering RNA.

A

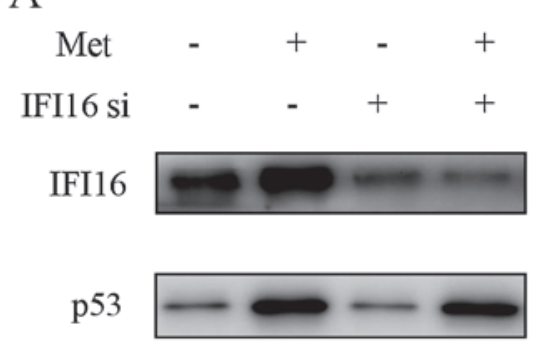

AMPK

p-AMPK
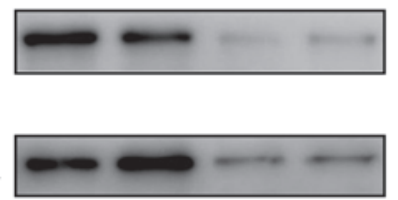

\section{GAPDH}

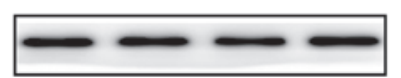

B
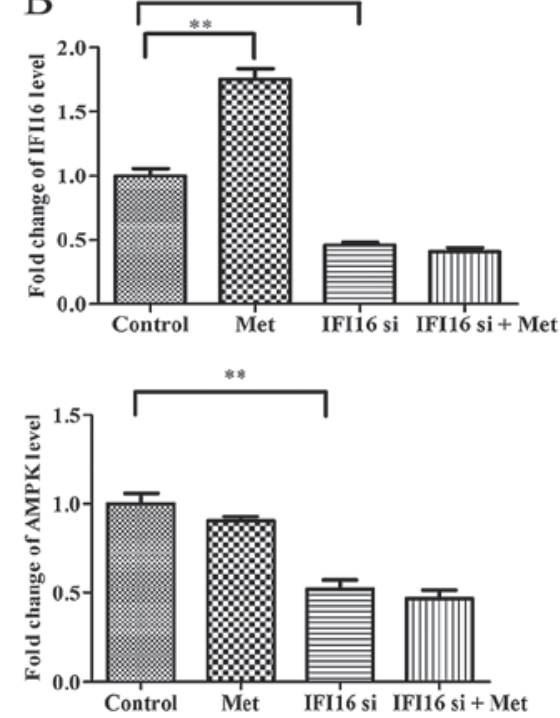
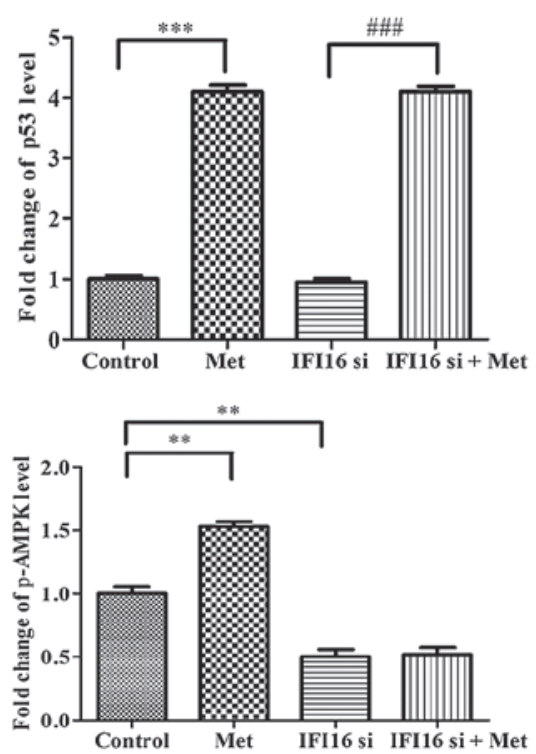

Figure 10. Met does not activate AMPK in IFI16-silenced HASMCs. Control HASMCs and IFI16-silenced HASMCs were treated with or without $10 \mathrm{mM}$ Met for 24 h. (A) Control HASMCs (control), control HASMCs treated with Met (met), IFI16-silenced HASMCs (IFI16 si) and IFI16-silenced HASMCs treated with Met (IFI16 si + Met) were lysed and examined by western blot analysis to detect IFI16, p53, AMPK and p-AMPK protein expression. (B) Histogram represents fold change in protein expression normalized to GAPDH relative to the control. All data are presented as the means \pm standard deviation from three independent experiments. ${ }^{* *} \mathrm{P}<0.01$ and ${ }^{* * *} \mathrm{P}<0.001$ vs. the control group; ${ }^{* \# *} \mathrm{P}<0.001$ vs. the IFI16 si group. AMPK, 5 ' adenosine monophosphate-activated protein kinase; HASMCs, human aortic smooth muscle cells; IFI16, interferon-inducible protein 16; p-, phosphorylated; si, small interfering RNA. 
p53 and IFI16 in primary HASMCs. Further in vivo studies are required to clarify the molecular mechanisms underlying the association between the suppressive effects of metformin and the ATM-p53-IFI16-AMPK pathway in HASMCs.

In conclusion, the present study indicated that metformin may inhibit HASMC proliferation and migration through activating the ATM-p53-IFI16-AMPK pathway. In addition, p53 and IFI16 may be required for metformin-mediated suppressive effects and activation of AMPK in HASMCs. These findings suggested that metformin could be considered a potential therapeutic agent used to reduce the risk of atherosclerosis.

\section{Acknowledgements}

The authors of the present study would like to thank the technological support of the Key Laboratory of Cardiovascular Remolding and Function Research, Chinese Ministry of Education, Chinese Ministry of Health in Qilu Hospital. The present study was supported by the National Natural Science Foundation of China (grant no. 81260030).

\section{References}

1. Lim S and Park S: Role of vascular smooth muscle cell in the inflammation of atherosclerosis. BMB Rep 47: 1-7, 2014.

2. Virmani R, Kolodgie FD, Burke AP, Farb A and Schwartz SM: Lessons from sudden coronary death: A comprehensive morphological classification scheme for atherosclerotic lesions. Arterioscler Thromb Vasc Biol 20: 1262-1275, 2000.

3. Rafieian-Kopaei M, Setorki M, Doudi M, Baradaran A and Nasri H: Atherosclerosis: Process, indicators, risk factors and new hopes. Int J Prev Med 5: 927-946, 2014.

4. Bennett MR, Sinha S and Owens GK: Vascular smooth muscle cells in atherosclerosis. Circ Res 118: 692-702, 2016.

5. Rudijanto A: The role of vascular smooth muscle cells on the pathogenesis of atherosclerosis. Acta Med Indones 39: 86-93, 2007.

6. Lusis AJ: Atherosclerosis. Nature 407: 233-241, 2000.

7. Ross R: The pathogenesis of atherosclerosis: A perspective for the 1990s. Nature 362: 801-809, 1993.

8. Crandall JP, Knowler WC, Kahn SE, Marrero D, Florez JC, Bray GA, Haffner SM, Hoskin M and Nathan DM; Diabetes Prevention Program Research Group: The prevention of type 2 diabetes. Nat Clin Pract Endocrinol Metab 4: 382-393, 2008.

9. Zhou G, Myers R, Li Y, Chen Y, Shen X, Fenyk-Melody J, Wu M, Ventre J, Doebber T, Fujii N, et al: Role of AMP-activated protein kinase in mechanism of metformin action. J Clin Invest 108: 1167-1174, 2001.

10. Ajjan RA and Grant PJ: Cardiovascular disease prevention in patients with type 2 diabetes: The role of oral anti-diabetic agents. Diab Vasc Dis Res 3: 147-158, 2006.

11. Wan X, Huo Y, Johns M, Piper E, Mason JC, Carling D, Haskard DO and Boyle JJ: 5'-AMP-activated protein kinase-activating transcription factor 1 cascade modulates human monocyte-derived macrophages to atheroprotective functions in response to heme or metformin. Arterioscler Thromb Vasc Biol 33: 2470-2480, 2013.

12. Wang Q, Zhang M, Torres G, Wu S, Ouyang C, Xie Z and Zou MH: Metformin suppresses diabetes-accelerated atherosclerosis via the inhibition of Drp1-mediated mitochondrial fission. Diabetes 66: 193-205, 2017.

13. Uitz E, Bahadori B, McCarty MF and Moghadasian $\mathrm{MH}$ : Practical strategies for modulating foam cell formation and behavior. World J Clin Cases 2: 497-506, 2014.

14. Vigetti D, Clerici M, Deleonibus S, Karousou E, Viola M, Moretto P, Heldin P, Hascall VC, De Luca G and Passi A: Hyaluronan synthesis is inhibited by adenosine monophosphate-activated protein kinase through the regulation of HAS2 activity in human aortic smooth muscle cells. J Biol Chem 286: 7917-7924, 2011.

15. Kim SA and Choi HC: Metformin inhibits inflammatory response via AMPK-PTEN pathway in vascular smooth muscle cells. Biochem Biophys Res Commun 425: 866-872, 2012.
16. Storozhuk Y, Hopmans SN, Sanli T, Barron C, Tsiani E, Cutz JC, Pond G, Wright J, Singh G and Tsakiridis T: Metformin inhibits growth and enhances radiation response of non-small cell lung cancer (NSCLC) through ATM and AMPK. Br J Cancer 108: 2021-2032, 2013

17. Rufini A, Tucci P, Celardo I and Melino G: Senescence and aging: The critical roles of p53. Oncogene 32: 5129-5143, 2013.

18. McCubrey JA and Demidenko ZN: Recent discoveries in the cycling, growing and aging of the p53 field. Aging (Albany NY) 4: 887-893, 2012.

19. Wang J, Deng Y, Tan Y, Li K, Wen B and Zhao Q: Cannabinoid WIN55, 212-2 inhibits proliferation, invasion and migration of human SMMC-7721 hepatocellular carcinoma cells. Xi Bao Yu Fen Zi Mian Yi Xue Za Zhi 32: 619-624, 2016 (In Chinese).

20. Li P, Zhao M, Parris AB, Feng X and Yang X: p53 is required for metformin-induced growth inhibition, senescence and apoptosis in breast cancer cells. Biochem Biophys Res Commun 464: 1267-1274, 2015.

21. Cerezo M, Tichet M, Abbe P, Ohanna M, Lehraiki A, Rouaud F, Allegra M, Giacchero D, Bahadoran P, Bertolotto C, et al: Metformin blocks melanoma invasion and metastasis development in AMPK/p53-dependent manner. Mol Cancer Ther 12: 1605-1615, 2013.

22. Cai X, Hu X, Tan X, Cheng W, Wang Q, Chen X, Guan Y, Chen $C$ and Jing X: Metformin induced AMPK activation, G0/G1 phase cell cycle arrest and the inhibition of growth of esophageal squamous cell carcinomas in vitro and in vivo. PLoS One 10: e0133349, 2015.

23. Chen HP, Shieh JJ, Chang CC, Chen TT, Lin JT, Wu MS, Lin JH and Wu CY: Metformin decreases hepatocellular carcinoma risk in a dose-dependent manner: Population-based and in vitro studies. Gut 62: 606-615, 2013.

24. Zhuang Y and Miskimins WK: Cell cycle arrest in metformin treated breast cancer cells involves activation of AMPK, downregulation of cyclin D1, and requires $\mathrm{p} 27^{\mathrm{Kip} 1}$ or $\mathrm{p} 21^{\mathrm{Cip1}}$. J Mol Signal 3: 18, 2008.

25. Kim EJ, Park JI and Nelkin BD: IFI16 is an essential mediator of growth inhibition, but not differentiation, induced by the leukemia inhibitory factor/JAK/STAT pathway in medullary thyroid carcinoma cells. J Biol Chem 280: 4913-4920, 2005.

26. Song LL, Alimirah F, Panchanathan R, Xin H and Choubey D: Expression of an IFN-inducible cellular senescence gene, IFI16, is upregulated by p53. Mol Cancer Res 6: 1732-1741, 2008.

27. Duan X, Ponomareva L, Veeranki S and Choubey D: IFI16 induction by glucose restriction in human fibroblasts contributes to autophagy through activation of the ATM/AMPK/p53 pathway. PLoS One 6: e19532, 2011.

28. Livak KJ and Schmittgen TD: Analysis of relative gene expression data using real-time quantitative PCR and the 2(-Delta Delta C(T)) Method. Methods 25: 402-408, 2001.

29. Vasamsetti SB, Karnewar S, Kanugula AK, Thatipalli AR, Kumar JM and Kotamraju S: Metformin inhibits monocyte-to-macrophage differentiation via AMPK-mediated inhibition of STAT3 activation: Potential role in atherosclerosis. Diabetes 64: 2028-2041, 2015.

30. Ding WX: Uncoupling AMPK from autophagy: A foe that hinders the beneficial effects of metformin treatment on metabolic syndrome-associated atherosclerosis? Focus on 'glucose and palmitate uncouple AMPK from autophagy in human aortic endothelial cells'. Am J Physiol Cell Physiol 308: C246-C248, 2015.

31. Rakesh K and Agrawal DK: Cytokines and growth factors involved in apoptosis and proliferation of vascular smooth muscle cells. Int Immunopharmacol 5: 1487-1506, 2005.

32. Selzman CH, Miller SA, Zimmerman MA, Gamboni-Robertson F, Harken AH and Banerjee A: Monocyte chemotactic protein-1 directly induces human vascular smooth muscle proliferation. Am J Physiol Heart Circ Physiol 283: H1455-H1461, 2002.

33. Sarfstein R, Friedman Y, Attias-Geva Z, Fishman A, Bruchim I and Werner H: Metformin downregulates the insulin/IGF-I signaling pathway and inhibits different uterine serous carcinoma (USC) cells proliferation and migration in p53-dependent or -independent manners. PLoS One 8: e61537, 2013.

34. Clarke CJ, Hii LL, Bolden JE and Johnstone RW: Inducible activation of IFI 16 results in suppression of telomerase activity, growth suppression and induction of cellular senescence. J Cell Biochem 109: 103-112, 2010.

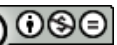

This work is licensed under a Creative Commons Attribution-NonCommercial-NoDerivatives 4.0 International (CC BY-NC-ND 4.0) License. 